\title{
GEOGRAPHIC INFORMATION SYSTEM (GIS) AND ITS APPLICATION IN URBAN PLANNING AND ENVIRONMENT
}

\author{
Masood Safari Ali Akbari ${ }^{1}$ \\ ${ }^{\prime}$ Department of Geography, Payame Noor University (PNU), Tehran, I.R. of Iran
}

\begin{abstract}
Using satellite data and GIS, the location of various urban land uses, including new methods for locating is quick. This study, based on a method of analysis - descriptive, and benefit from the resources in this area to assess the effectiveness of GIS in urban planning and environment, is discussed, and attempted to make a clear point of view, this can provide. Our results indicate that, nowadays, several researchers, from capabilities of GIS are used for localization. Because GIS is able to analyze large amounts of data layers is. Use of GIS in urban planning, with the rapid expansion of cities and increased levels of SAM binding information that must be processed for urban management, is clear. Abnormal location for the development of suitable sites for the establishment of urban green spaces, places for waste disposal and land evaluation, and its features and many other environmental issues, it can be pointed out.
\end{abstract}

Keywords: GIS, Management, Application of GIS, Town planning, Increased efficiency of urban, Management urban, Environment.

Received: 24 May 2014/ Revised: 5 June 2014/ Accepted: 10 June 2016/ Published: 13 June 2014

\section{INTRODUCTION}

Urbanization is one of the most important phenomena of our age. So far, the talk of the town in the world to be. Since a complete and rational planning, development and management of urban improvements, several sources, including sources for urban development, social capital and natural, must also be considered, so the data is accurate and updated needs. Therefore, geographic information systems able to provide accurate information, and the right time to help planners and decision-makers. Today, the city determined that the public, professionals and executives, management and administration of the various towns with traditional tools is impossible. Use of GIS in urban planning, with the rapid expansion of cities and increased levels of SAM binding information that must be processed for urban management, it is clear (Farajzadeh Asl and Sarvar, 2002). Using satellite data and GIS, the location of various urban land uses, including new 
methods for locating is quick. Recently, several researchers the ability of GIS, are used for localization.

Because GIS is able to analyze large amounts of data layers are, on the other, the most important feature of GIS, it as a special, separate from other automated systems will The ability to integrate data modeling, locate and determine the appropriateness of the land, the land is valued mapping. The result of integrating and combining criteria, the best place to locate the centers, and the optimal location is chosen (Fataii and Alsheikh, 2009). The dramatic expansion of urbanization, coupled with the development of cities in terms of population and land area, and the creation of metropolitan, urban create different textures and combinations, communications, and economic factors are complex. Human impact on the environment, increasingly from the effects of urban life arises due to the growth of the human population, and partly the result of the ascendancy of technology on human life. Although urbanization has positive economic and social effects, but the problems and issues in turn is fueled by urban residents, where they can be as urbanization problems, in the present age into account. (Qalibaf, 2009).One of the advanced tools and modern science, urban management, geographic information systems, and related techniques, which rely on them even a few million prospects metropolises, so translucent that, while carrying out all construction activities and services, with a minimum traverse time and space, as well as related information can be combined with layers, various activities and functions in parallel with the organizations the opportunity exploitation of a fee, to a couple of different activities and consequently reduce costs, avoid duplication, and better efficiency of services provided.

Of information systems, which can be used as a basis for the formulation of all infrastructure, in order to regulate construction activities, services, social and cultural cities, they have a fundamental importance, or lack thereof, even if not in the present circumstances metropolitan barrier any activity to be comprehensive, that is, at least, it would increase the cost of these activities. GIS provides such information, and the directors of different departments put up at the same time that any manager is well aware of the conditions in place to expand its operations, along with other activities in other parts of the area where the directors met and they adapt their (Moini, 2001).

\section{GEOGRAPHIC INFORMATION SYSTEM}

GIS is an important tool and Sciences, Geography Today, they are used to analyze the data. This system began in 1960, and over the past 50 years, its place in science that somehow the earth has to deal with (Farajzadeh Asl, 2005) So far, many definitions of GIS, provided. These definitions are mainly two approaches to technology-based, problem-based approach arises (Malczews ki, 1999). 's Approach is based on technology, GIS is defined as a set of tools for storing, retrieving processing and analysis of spatial data, and the output of the spatial data, is applied. (Zewen et al., 1990) the ultimate goal of the GIS, creating a system to decide knew the back. The system is the problem, in the receiver, integrated collection of data that arise in spatial dimensions. 
The way in which data is entered in a GIS environment, storage and analysis, they must process the data in relation to a particular task, and the task of sorting a decision, was used. GIS can be divided into four parts or sub- systems:

1. Data entry (including identification and data collection)

2. Storage and data management

3. Implementation, implementation, processing and analyzing data

4. Output data

\section{THE OVERALL STRUCTURE OF THE GIS}

The overall performance of these systems, so that, at first location and a description of the geographical side, through various methods, collected, and the different layers of information, may be stored in a central system. The various operations (such as topology, overlapping, etc.) performed on these layers, or processing logic and mathematical analysis, the desired results are achieved. Ultimately results in the form of graphs, tables and maps will be available at (Mirzabayati, 2004).

\section{URBAN MANAGEMENT AND GIS}

One of the main activities of interest to urban planners, land location and service spaces, in order to deploy them in the most appropriate and the best possible location and status. Thus, one of the most practical tasks of GIS in determining patterns of urban land use, particularly in urban management appears. Allocation of urban space users, serve and evaluate, and deploy the most ideal type of user, and also the arrangement of land uses, consistent and appropriate manner, the most fundamental issues in urban management system is. Cities formed in the past, mostly with no discipline, and a good homogeneity in the distribution of land, usually not. Density of undesirable land uses in the city and its variations, the problems that exist in the city. Today, the main goals of land use on its values of sustainable development and improving the quality of urban life is stable.

The balance of the land, Following which the optimal management services, and an increase in urban incomes, and improving the quality of human life and the environment, urban management is the main goal. In this case, various tools such as GIS, is a very useful and efficient. Cities have always been a dynamic element in human history, there have been continuous developments and changes, and the ultimate goal of planners to raise the level of welfare of the people and solve their problems and difficulties in urban communities as's. Accordingly, planners have tried, by providing scientific and practical models and strategies, and the use of new techniques to deal with problems. Among the issues that should be considered by planners, urban affairs, determination of solutions, in order to optimize the location of urban centers to reach citizens in urban development plans. In larger cities, traffic is a major problem, mainly due to an incorrect location, urban services. Therefore, the correct location, in urban centers, especially in cities, big cities, in the context of urban planning, a dynamic and flowing with the daily movements, interactions and functions of urban elements, in addition to providing economic 
savings, citizens of time, a healthy environment and good life that the city planners have brought. In GIS, the dimensions of today's complex urban issues, and the different variables involved in urban planning, different software models, can be used in urban planning. The main role of GIS, urban management can be mentioned the following:

- An important tool in the direction of urban information

- Choose the type of tool for analyzing, planning, programming or desirable

- A guide for decision makers, municipal officials and organizations, to reduce the losses from disasters

- A technical device to help implement those decisions

- Planning for emergencies and disasters nature

- Environmental monitoring, and enforcement of its provisions

- Control of the city's tax affairs

- Proper maintenance of pavements and highways

- Control of air pollution, noise pollution, and identify sources of pollution

- Regulation of traffic, and the roads leading into the city

- Analysis of stress - emotional stress and the city illnesses

- Using GIS, urban policy, and...

Benefits of GIS in Urban Planning and Management:

Prevent disputes about property and land in cities

Determine the exact reconstruction property after accident

Prevention of fraud in connection with real

Careful management of taxes, such as sales tax revenue, renewal of property and...

Suitable for other urban management, for example, to find the optimum area for green space, schools, creating new shops and...

Detailed knowledge of the real estate agents, real estate conditions in your work area, such as commercial property and residential rental...

a series of questions to be answered and, according to the expressed needs of the client and users.

Some important questions are:

Which land, certain registers are located in the area?

Properties of a specific owner, enter the city?

Properties that are of a certain user can specify?

Piece of land with an area larger than a certain amount, and you can specify are empty?

Green spaces in urban areas you specify?

Land that, at a certain distance from the road are specifying?

Nearest urgent to your specific situation?

Outcomes resulting from these questions can include a variety of charts, maps and statistical tables are displayed. Stated clearly that, whatever layers in geographic information systems, is becoming more diverse, we have a system of questions and answers and more. GIS systems have different input and output (Figure 1) 
Figure-1. Input Output System GIS

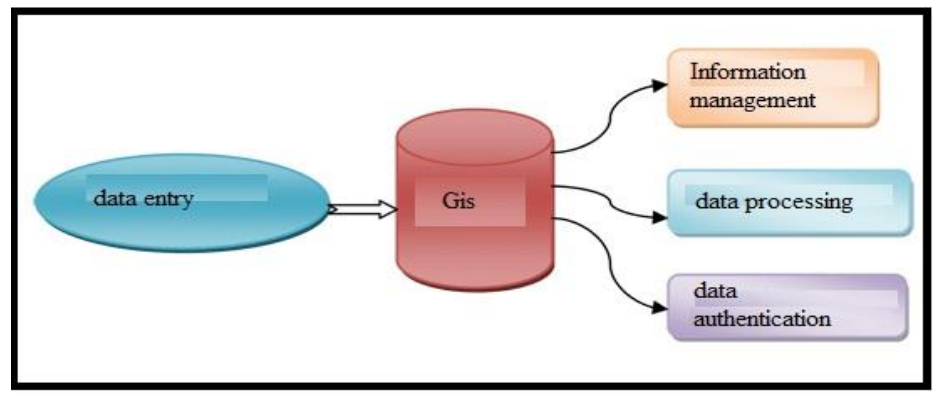

Using Geographic Information System, in addition, in urban management, effective managers and helps in making the right decision, economically, particularly in the financial sector, will lead to a great deal of interest (Haghgoo, 2012).

\section{ACCOUNTING, MAINTENANCE AND DESIGN OF MUNICIPAL UTILITIES}

GIS capabilities can be used to organize; store and design of municipal utilities, such as electricity grids, water and sewage, and telecommunications are also noted. Organize and maintain the network map, municipal utilities, and base maps, facilities, utilities for the network accurately design, build customer databases, and related to their location on the map, creating a database of applicants, and ultimately forecasting needs, through Statistical maps, plan to develop networks, and better and more precise control over development initiatives, the most important achievements of GIS is the management of municipal utilities, which must be in the planning, development, managers and planners should consider. Therefore, the above description, the use of GIS in organizations such as municipalities, the direct and indirect supervision of the management and urban development, including supplies that should be considered by officials and planners.

\section{DETERMINATION OF OPTIMAL URBAN LOCATIONS}

Nowadays, due to the growing urban population, and the lack of adequate space for activities, and facilities needed to determine the optimal location of urban land uses, according to various variables, in urban planning using GIS, which is one of the most powerful systems, studies and practical needs, be done. Determining the appropriate locations for various land uses in the city), residential, commercial, industrial, office), and... Reduce unnecessary travel within the city, causing minimal adverse effects on the environment, and reduce economic costs, will have a significant role (Adl, 2012) (Figure 2). 
Figure-2.

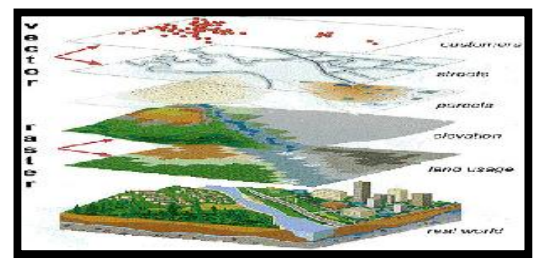

\section{APPLICATION OF GIS, THE INCREASED EFFICIENCY OF URBAN} MANAGEMENT

Just as the invention of the steam engine, could transform the shipping industry, without a doubt, the approach of geographic information systems, the future of urban management will be faced with deep and fundamental. The management of GIS, the city manager, it can give, just a simple application, go to the street level, or above it, flying, and the prospect of streets, embankments, water Collection on them, Microclima different areas of the city, traffic and space patterns, and many others, even to the activities of a particular social group, in a view. Using this software, GIS, multi-dimensional model can be obtained from the city, and upon the payment of large future project design. All cities so far, have been able to use geographic information systems, productivity in the service sectors, and reducing costs are viewing. Some of the benefits of GIS, the long-term functions are visible, which can be pointing to some of them: reduce the cost of doing things more efficiently, and in less time, reduce costs, organizations are. These savings can be realized directly in budget cuts.avoid the expense of future costs due to high increase in workload process is prevented. municipalities and local authorities, who are faced with rapid growth, or decline, housing and infrastructure experience, are functions that operate in the future increases.

Increased revenue: GIS can earn municipality or local entity, with plans to increase sales and. The system can also increase the effects of acquisitions, and improving the quality of information is associated with (Moradianan and Namin, 2012).

\section{APPLICATION OF GIS, IN IMPROVING THE URBAN ENVIRONMENT}

To protect the environment, and to meet human needs, the information is updated and correct decisions are required. Accurate data collection, one of the biggest challenges facing governments and private organizations responsible for, the decisions are. System GPS, which helps to meet this need. Information systems, collecting data, and accurate positioning data, the nature of the items that are spread throughout the area, to provide a decision-making organizations. Connect positioning data, the information in the fields, the possibility of the city's many environmental problems, allows the other aspects. Data collected by GPS can enter geographic information system software (GIS), is the possibility that the spatial analysis, with the information, through wider, in order to understand the specific location provided. Aerial surveys some of the most impenetrable natural and human systems to support GPS, a way to explore the environment, and also provides a smooth man-made infrastructure. Putting together the aerial images, a region with coordinates obtained from GPS, able to assess efforts to protect the 
environment, and the overall plan will be adopted. Technology, GPS, as we predict environmental changes, will help. By combining the measurements of GPS, the method of operation used by meteorologists can determine the amount of water in the earth, and this will increase the accuracy of weather forecasts. Moreover, the increase in tidal tracking database, allowing direct observation of the effects of tidal waves, oceans, especially coastal cities, provides. Receivers installed on marine vessels, movement and spread of the oil spill on the sea, they are tracking. The helicopters using GPS, forest fires in the drawing environment, and enables efficient use of resources, fire extinguisher provides. Migration patterns of species, endangered species, such as gorillas in Rwanda, by GPS, tracking, and are drawn, and it helps to overpopulation. In earthquake prone areas, like the edges of the Pacific, the system GPS, a very important and vital role in the prediction of earthquake potential plays. Accurate positioning information using GPS, scientists were able to study the stresses in the layers of the earth, with time, which is to identify the characteristics and possible future earthquake prediction, resulting in high-risk cities. Another advantage of GIS, production timing is critical. Data, GPS, because they are digital, and are also available in all parts of the world, can be analyzed quickly. This means that, for the analysis is complete, just need several hours or days, not weeks or months. Thus, ensuring that the final product will be ready in time can be achieved. Given the fast pace of change in today's world, it can save time, is vital for the city. Modernize GIS, survey and management of the urban environment, increases. United States, adding two additional civilian signals that applications environment with accuracy, accessibility and provide greater certainty. For example, the possibility of studying the ecology of tropical rain forests, with increased access to the system, GPS, and its use in GIS, urban areas with dense vegetation, increases.

\section{Figuer-3.}

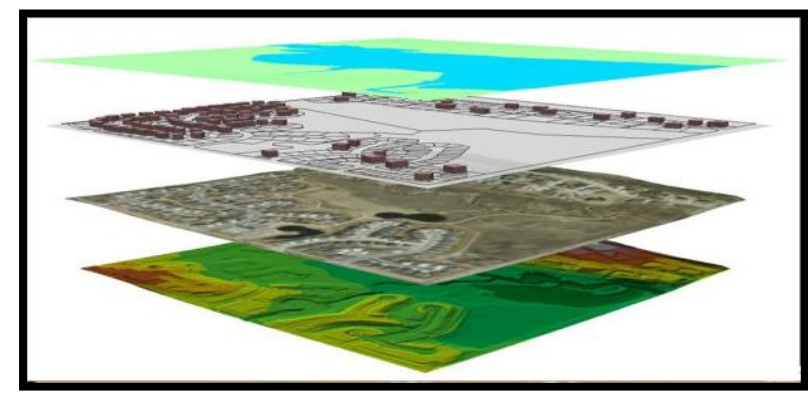

\section{CONCLUSIONS}

Complex urban issues, and the wide range and variety of data and information required ) to use the data ( for urban development and management, has created a situation where, city managers today need hard data, and identify the level of influence each Since, GIS Iran poses new knowledge, growing urbanization, and the significant increase in activities related to the environment and spatial planning) how urban environments and natural environments ( we are forced to become familiar with the knowledge, and most of the to invest. scope of services that 
GIS, offers the urban environment, and in this sense can come to the aid of the service sector managers, shows that, in the future urbanization, GIS will play a larger and more important role. role of GIS, utilities in increasing productivity, management, strategy formulation and presentation of information is important, and the maximum efficiency is desired. According to the cases mentioned above, it is proposed that:

Since the creation of urban management system, the GIS, a direct correlation with the quality and detail of information is necessary, place the information needed to accurately picked, and descriptive profile is complete, to allow a better analysis of the city environment as possible.

Worthy that, for better analysis and management of the environment, the ideal model of the city and its associated database should be established, and in relation to different topics used, it is necessary for city managers with GIS, familiar have to take appropriate measures on urban management and good quality service pay.

Funding: This study received no specific financial support.

Competing Interests: The author declares that there are no conflicts of interests regarding the publication of this paper.

\section{REFERENCES}

Adl, M., 2012. GIS Applications in Planning and Sustainable Management of Urban Planning and Environmental Management Conference Proceedings.

Farajzadeh Asl, M., 2005. GIS and its application in tourism planning, Publishing Side, Tehran-IRAN.

Farajzadeh Asl, M. and H. Sarvar, 2002. The management and location of training centers, using GIS. Journal of Geographical Research, 67: 120-135.

Fataii, I. and A. Alsheikh, 2009. Locating in urban waste disposal, using GIS, and the analytic hierarchy process, case study: Givi city. Journal of Environmental Sciences, 6(3): 145-158.

Haghgoo, S., 2012. GIS in urban planning. Proceedings of the Second Conference on Planning and Environmental Management. Tehran-IRAN.

Malczews ki, J., 1999. GIS and multicriteria decision analysis. London: John Wiley \& Sons Publications.

Mirzabayati, R., 2004. Feasibility of saffron -prone areas, Neishaboor plain using GIS. Master's Thesis in Environmental Planning Climatology, Tarbiat Modarres University. IRAN.

Moini, S.M.M., 2001. Application of GIS to increase productivity batch utilities, Bimonthly city, 3(21): 1-20.

Moradianan, F.M. and A.I. Namin, 2012. Application of GIS in Urban Environmental Management.

Qalibaf, M.B., 2009. Doctrine Tehran urban management and the environment. Democracy Journal, 4(2): 20-28. [Accessed 7 Oct 2009].

Zewen, L., J. Dong, L. Denghuai and Z. Cuizhi, 1990. The estimation of cottongrowing areas by Remote Sensing. Asian Conference on Remote Sensing. Review.

Views and opinions expressed in this article are the views and opinions of the author(s), International Journal of Geography and Geology shall not be responsible or answerable for any loss, damage or liability etc. caused in relation to/arising out of the use of the content. 